Article

\title{
X-ray Diffraction Investigation of Stainless Steel-Nitrogen Thin Films Deposited Using Reactive Sputter Deposition
}

\author{
Faisal I. Alresheedi ${ }^{1,2}$ and James E. Krzanowski ${ }^{3, *}$ \\ 1 Physics Department, University of New Hampshire, 9 Library Way, Durham, NH 03824, USA; \\ fia1@wildcats.unh.edu \\ 2 Department of Physics, College of Science, Qassim University, Buraidah 51452, Saudi Arabia \\ 3 Mechanical Engineering Department and Materials Science Program, University of New Hampshire, \\ 33 Academic Way, Durham, NH 03824, USA \\ * Correspondence: James.Krzanowski@unh.edu; Tel.: +1-603-862-2315
}

Received: 15 September 2020; Accepted: 12 October 2020; Published: 15 October 2020

check for updates

\begin{abstract}
An X-ray diffraction investigation was carried out on nitrogen-containing 304 stainless steel thin films deposited by reactive rf magnetron sputtering over a range of substrate temperature and bias levels. The resulting films contained between $\sim 28$ and 32 at.\% nitrogen. X-ray analysis was carried out using both the standard Bragg-Brentano method as well as area-detector diffractometry analysis. The extent of the diffraction anomaly ((002) peak shift) was determined using a calculated parameter, denoted $R_{B}$, which is based on the (111) and (002) peak positions. The normal value for $R_{B}$ for FCC-based structures is 0.75 but increases as the (002) peak is anomalously displaced closer to the (111) peak. In this study, the $R_{B}$ values for the deposited films were found to increase with substrate bias but decrease with substrate temperature (but still always $>0.75$ ). Using area detector diffractometry, we were able to measure $d_{111} / d_{002}$ values for similarly oriented grains within the films, and using these values calculate $\mathrm{c} / \mathrm{a}$ ratios based on a tetragonal-structure model. These results allowed prediction of the $(002) /(200)$ peak split for tetragonal structures. Despite predicting a reasonably accessible split $\left(\sim 0.6^{\circ}-2.9^{\circ}-2 \theta\right)$, no peak splitting observed, negating the tetragonal-structure hypothesis. Based on the effects of film bias/temperature on $R_{B}$ values, a defect-based hypothesis is more viable as an explanation for the diffraction anomaly.
\end{abstract}

Keywords: sputter deposition; thin films; X-ray diffraction; expanded austenite

\section{Introduction}

Since the initial discovery of the S-phase by Zhang and Bell [1] and Ichii et al. [2], understanding the structural nature of this phase and the anomalous shift of the (200)/(400) diffraction peaks has been a challenging problem. The S-phase (also termed "expanded austenite") was discovered as a result of research aimed at creating a nitrogen-enriched surface layer on stainless steels for improved wear resistance. In the mid-to-late 1990's much of the research was centered on the investigation of low-temperature plasma nitriding methods [3-10] and the development of surface hardening methods via a combination of nitrogen implantation and diffusion. These processes generally are carried out within the temperature range of $250-400{ }^{\circ} \mathrm{C}$; at temperatures above $400, \mathrm{CrN}$ forms, depleting the matrix of $\mathrm{Cr}$ and reducing corrosion resistance, while below $250{ }^{\circ} \mathrm{C}$ nitrogen diffusion is too slow to form a surface layer of significant depth. Numerous studies on plasma nitriding methods for stainless steels have been reported including ion beam implantation [3-5] and the plasma immersion implantation method [5-10]. Structural characterization of treated surfaces revealed the formation 
of the S-phase, and a significant degree of surface hardening was observed along with substantial reductions in wear rates.

In addition to plasma nitriding methods, the S-phase can be produced by sputter deposition from stainless steel targets in a nitrogen-containing atmosphere [11-16]. Saker et al. [11] and Bourjot et al. [12] reported deposition of "stainless-steel nitrogen" coatings deposited by triode reactive magnetron sputtering from 310 stainless targets. A nitrogen content of up to $42 \%$ was obtained and the S-phase was confirmed by $\mathrm{X}$-ray diffraction. The microhardness was measured and the maximum was reported as $15 \mathrm{GPa}$ at a nitrogen concentration of about $15 \%$. Shedden at al. [13] deposited coatings from 316 stainless steel using magnetron sputtering and a substrate temperature of $350{ }^{\circ} \mathrm{C}$. They found the nitrogen content in the films increased with the proportion of $\mathrm{N}_{2}$ in the sputtering gas, and reached a maximum of about $40 \%$. The films had a very strong $<100>$ fiber texture, although the fiber axis tilted away from the substrate normal at the highest $\mathrm{N}_{2}$ flow rates. In addition, they examined the formation of energetic neutrals during sputtering and showed the yield of nitrogen energetic neutrals was much greater than that for argon. Therefore, as nitrogen content of the sputter gas increased, the burial of nitrogen within the growing films also increased, indicating enrichment with nitrogen was a primarily dynamic phenomenon.

The nitrogen content in the films described above were all sub-stoichiometric, i.e., with N/Me $<1$, and contained up to $40 \%$ nitrogen. However, higher nitrogen concentrations have been obtained by increasing the percentage of $\mathrm{N}_{2}$ in the sputtering gas during deposition. Kappaganthu and Sun [15] deposited films from a 316L target in an $\mathrm{Ar}+\mathrm{N}_{2}$ mixture with nitrogen contents ranging from 0 to $75 \%$ (at a constant sputtering pressure of $0.67 \mathrm{~Pa}$.) The nitrogen content in the films increased with the -percent $\mathrm{N}_{2}$ in the gas mixture and reached a maximum of $50 \%$ film nitrogen at $\mathrm{N}_{2}$ content of $50 \%$ and higher. For film nitrogen concentrations between $35 \%$ and $45 \%$, the (200) peak position anomaly was observed; however, for films with $50 \%$ nitrogen the d-spacings measured were all consistent with a single lattice parameter. The $\mathrm{MeN}(\mathrm{Me}=\mathrm{Fe}, \mathrm{Cr}, \mathrm{Ni}$ and $\mathrm{Mo}$ ) phase was proposed to have a zinc-blende type structure. Kappaganthu and Sun [16] also examined the effect of substrate temperature and found that deposition at $300{ }^{\circ} \mathrm{C}$ promoted single-phase S-phase formation, but at $400{ }^{\circ} \mathrm{C}$ some $\mathrm{CrN}$ formation was observed.

The (200)/(400) peak position anomaly (characterized by observations where the position of the (200)/(400) peaks are inconsistent with the remaining peaks in the XRD patterns) has puzzled investigators for over 30 years, and there is still no consensus on the structural features of the S-phase that cause this peak shift. However, four main explanations have been proposed: (1) the S-phase is not a single phase but consists of multiple phases; (2) the structure is not FCC but rather (slightly) distorted into a tetragonal, monoclinic or other structure; (3) the anomaly is due to a high density of stacking faults; and (4) the anomaly results from a very large anisotropy in elastic constants. Early investigations by Marchev et al. $[17,18]$ led to the claim that the S-phase has a tetragonal structure, and in fact, they re-named the structure as the "m-phase" due to its similarity to bct martensite. In this case, the X-ray diffraction patterns should show split (200)/(002) peaks. However, no such peak split was observed, but its absence was attributed to the pronounced crystallographic texture (in this case a (111) orientation) in the samples. Bacci et al. [19] also claimed that an fct-structured S-phase provided a reasonable fit to their diffraction data, but the presence of the S-phase in the form of a compositionally-varying diffusion layer, well as iron nitride phases, complicated the analysis.

To further examine the possibilities of non-cubic structures, Fewell et al. [20] conducted TEM and XRD studies of plasma-nitrided AISI316 steel. In addition to the traditional Bragg-Brentano XRD method, they used a second beam angle (non-zero $\psi$ ) in order to measure a set of d-spacings for the same grain orientations (relative to the surface). They found no evidence for multiple phases and noted that the diffraction data again showed only expanded (200) and (400) planes. Attempts were made to rationalize this in terms of tetragonal, monoclinic and triclinic structures. The triclinic gave the best fit to the diffraction data; however, due to the broadening of the S-phase peaks, a definitive conclusion could not be made. Fewell and Priest [21] then examined the S-phase using synchrotron 
radiation, allowing them to conduct higher-order diffractometry and d-spacing measurements out to the (622) planes. They presented an extensive analysis of numerous non-cubic structures, but found that none of them worked well in matching the higher-order reflections.

Numerous investigations have pointed to stacking faults (on $\{111\}$ planes of the fcc structure) or other defects as an explanation for the diffraction anomaly [22-24]. The basis of this approach is the theoretical analysis presented by Warren [25] who determined the effect of stacking faults on the peak positions. The peak shifts were given in terms of the stacking fault density $\alpha(1 / \alpha$ is the number of planes between faults) and ( $h \mathrm{kl}$ )-dependent constants. In most cases, the value of $\alpha$ is determined based on the $\Delta 2 \theta$ calculated from the peak shift in the (200) reflection. For example, Blawert et al. [22] found $\alpha=0.167$ for their nitrogen expanded austenite samples; Christiansen and Somers [23] used $\alpha \sim 0.03$ to obtain results consistent with their data; and while $\mathrm{Xu}$ et al. [24] did not give a specific value for $\alpha$, they noted it should be dependent on nitrogen content. In order to unambiguously test the stacking fault hypothesis, it would be necessary to independently measure the stacking fault density $\alpha$, and compare the calculated $\Delta 2 \theta$ values with the observed shifts. However, this does not appear to have been done in any of the above studies, although stacking faults have been observed in several TEM studies. Xu et al. [26] and Stroz and Psoda [27] both examined the microstructure of plasma nitrided samples and observed stacking faults in the S-phase; the high-resolution image in the latter study showed stacking fault bundles with $\alpha \sim 0.1$. Nonetheless, they proposed the peak shift was due to a slight rhombohedral distortion in the lattice. The stacking fault explanation has been criticized in a number of papers $[26,28]$ due to the fact that Warren's model becomes inaccurate at high values of $\alpha$. A more detailed analysis of stacking fault effects was carried out by Velterop et al. [29]. However, the general effects described by Warren still hold, and for the (200) reflections only slight changes to the calculated $\Delta 2 \theta$ values appear to be necessary. Another problem with the stacking fault theory is that for the (400) reflections the peaks should shift in the opposite direction (to higher angles). However, careful measurements, such as those made by Fewell and Priest, show a decrease in the (400) position which is similar in magnitude to the (200) shift. Therefore, the stacking fault hypothesis does not seem consistent with much of the data.

The final explanation for the diffraction anomaly is the elastic anisotropy hypothesis. Grigull and Parascandola [30] carried out a residual stress analysis for the S-phase layer to determine the strain perpendicular and parallel to the surface. The residual stress increased dramatically with nitrogen content in the layer, and at $23 \% \mathrm{~N}$ the (compressive) stress was 2.5-3 GPa. Abrasonis et al. [31] found the strain in (100) oriented grains (relative to the surface) to be twice that of (111)-oriented grains. However, they used elastic constants for nitrogen-free austenitic stainless steel, since the elastic constants of the S-phase are not known. Nonetheless, they suggested that the combination residual stress and stacking fault effects could explain the diffraction anomaly.

The possibility of ordering of nitrogen atoms on the interstitial sublattice has been considered and potential evidence for such ordering was recently presented by Brink et al. [32]. The presence of such ordering would require indexing of diffraction patterns based on a larger unit cell, and this unit cell could have a distorted (non-cubic) shape. Ordering may also influence the distribution of metal atoms on the metal sublattice as shown in a recent EXAFS (Extended X-ray Absorption Fine Structure) study [33]. Another recent study by Czerwiec et al. [34], where Mössbauer spectroscopy was used to examine the detailed atomic structure in annealed 316L nitride samples, proposed that the structure consisted of two different environments: a one which was supersaturated with nitrogen, and another consisting of a martensitic environment without nitrogen.

In summary, the structure of the S-phase still remains controversial as none of the four hypotheses appears adequate to explain all of the observed results. A recent article by Christiansen et al. [35] concluded that stacking faults, composition gradients and residual stress gradients provided the best explanations the observed X-ray diffraction pattern anomalies in plasma treated bulk stainless steel samples. 
In this work, we analyze films sputter-deposited from 304 stainless steel targets in a nitrogen-containing atmosphere and characterize these samples using X-ray diffraction methods. The novelty of this work stems from the following observation: when the Bragg-Brentano method is employed, measured d-spacings for (111) and (200) planes are made from grains of different orientations. In this case, stress and elastic anisotropy effects can impact measured values. Ideally, measurements of both d-spacings should be made from grains of similar orientations. This was done by Fewell et al. [20] for select orientations. However, by using area detector diffactrometry a continuous range of orientations can be examined, which will be done here. We can then compare these results with those obtained using the Bragg-Bretano method. In addition, the possibility of a tetragonal-based structure will be examined.

In addition to insight gained from the use of area-detector diffractometry, the use of sputterdeposited samples deposited with variations in temperature and bias allow further understanding into the effects of composition and defect content on the structure of the S-phase [36]. For this purpose, samples will first be characterized using the Bragg-Bretano method, where the extent of the diffraction anomaly will be evaluated using the following term:

$$
R_{B}=\frac{\sin ^{2} \theta_{111}}{\sin ^{2} \theta_{200}}
$$

where $\theta_{111}$ and $\theta_{200}$ are the peak positions obtained (by definition) from an X-ray diffraction scan carried out using the standard Bragg-Bretano configuration, i.e., with $\psi=0$. The normal value of $R_{B}$ for an FCC structure is 0.75 , and a value of $R_{B}>0.75$ indicates that the sample has the S-phase structure.

Following this analysis we will consider the S-phase structure as nominally FCC (rocksalt structure) with a slight deviation along one cube direction resulting in a tetragonal structure. The assumption of tetragonality is taken to allow the parameter $c / a$ to be calculated based on the equation presented by Fewell and Priest [21], given by:

$$
\frac{c}{a}=\left(\frac{1}{2}\left[\frac{3 a_{002}^{2}}{a_{111}^{2}}-1\right]\right)^{1 / 2}
$$

Alternatively, this equation can be written in terms of d-spacings:

$$
\frac{c}{a}=\sqrt{\frac{2 d_{002}^{2}}{d_{111}^{2}}-\frac{1}{2}}
$$

Which is more amenable to direct calculation from X-ray diffraction data and makes no presumptions about the relationships between $a_{h k l}$ and $d_{h k l}$ values. Here we have assumed that the $c$-axis corresponds to the [001] direction and $c / a>1$. Using this equation, measurements of the (111) and (002) peak positions allow for determination of the $c / a$ ratio. This will be done using $d_{200}$ and $d_{111}$ values from the same grain, or grains of the same orientation.

The method devised for this purpose is illustrated in Figure 1, which shows a schematic diagram of a cross-section of a film with a typical columnar structure. We assume a fiber texture for the grain structure, and define the variable $\varphi$ as the angle of tilt of the [001] direction away from the nominal surface normal (substrate plane). Three cases are shown in the diagram. For grain 1, the grain orientation is [002] so that $\varphi=0^{\circ}$. The value of $d_{002}$ for this grain can be determined by conducting an XRD scan with $\psi=0$. However, to determine $d_{111}$ the scan needs to be run with $\psi=54.74^{\circ}$. For grain 2 , $\varphi=54.74^{\circ}$ but the value of $d_{111}$ is determined with $\psi=0^{\circ}$, and to find $d_{002}$ we set $\psi=54.74^{\circ}$. For grain 3 , we examine an intermediate orientation, in this case a grain with a [411] orientation. This gives $\varphi=19.5^{\circ}$, necessitating the use of $\psi=19.5^{\circ}$ to find $d_{002}$ and $\psi=35.27^{\circ}$ to find $d_{111}$. 


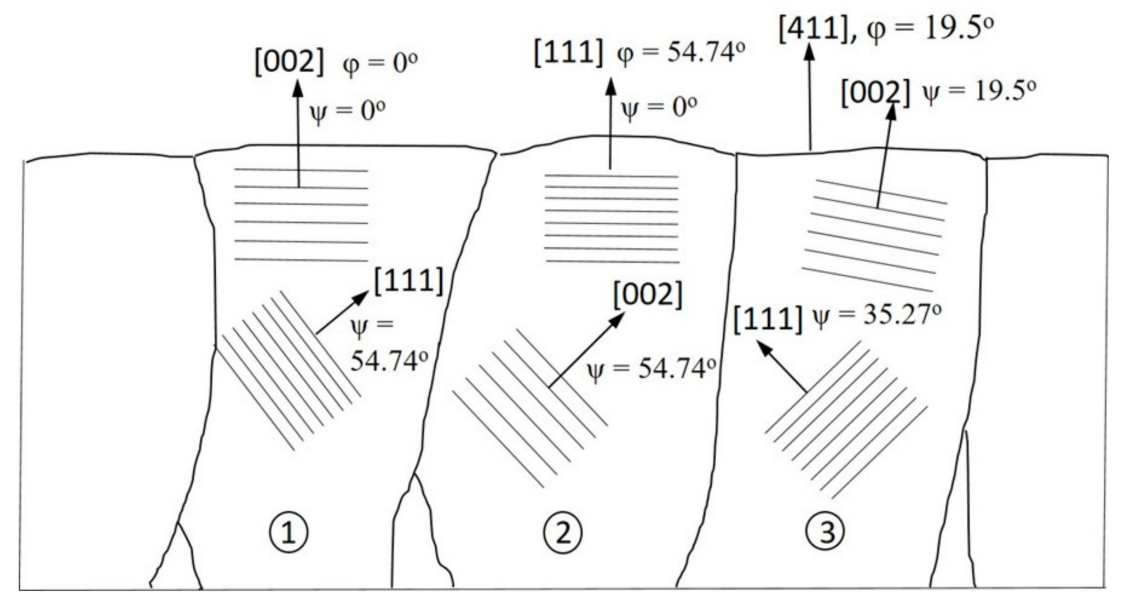

Figure 1. Schematic diagram of typical grain orientations showing the definitions of $\varphi$ and $\psi$ relative to the crystal structures and sample surface. The $\varphi$ angle is the angle of tilt away from the [002] direction in the crystal, whereas $\psi$ is the common diffraction vector, and is perpendicular to the surface in a Bragg-Brentano diffraction experiment.

In general, we can write:

For $d_{002}: \varphi=\psi$

For $d_{111}: \varphi=54.74-\psi$

Therefore, if we can find $d$ as a function $\psi$ for the (111) and (200) reflections, the above equations can be used to find $d_{h k l}$ vs. $\varphi$ and then determine $c / a$ using Equation (3). Using this procedure, we find $c / a$ as a function of $\varphi$. If there is no elastic anisotropy present, or in the absence of stress, $c / a$ should be constant with $\varphi$.

\section{Materials and Methods}

Films were deposited using rf-magnetron sputtering in a turbo-molecular pumped high vacuum system. The base pressure was $2 \times 10^{-6}$ Torr $(0.266 \mathrm{mPa})$ and the total gas pressure during sputtering was $5 \mathrm{mTorr}(0.67 \mathrm{~Pa})$. Si (100) wafers were used as substrates and 304 stainless steel was used for the target. The substrate-to-target distance was $12 \mathrm{~cm}$, with the sputter sources at an angle of $14^{\circ}$ from the substrate normal direction. The sputter power density was $7.5 \mathrm{~W} / \mathrm{cm}^{2}$, and the rf frequency was 13.56 MHz. In order to improve adhesion of films to the Si substrates, a metallic stainless steel film was first deposited in Ar at $-50 \mathrm{~V}$ bias to a thickness of $50 \mathrm{~nm}$. All nitride film depositions were carried out with $20 \mathrm{sccm} \mathrm{Ar} / 5 \mathrm{sccm} \mathrm{N} \mathrm{N}_{2}$ gas flow and a target-to-substrate distance of $60 \mathrm{~mm}$. The typical film thickness was $2.5-3 \mu \mathrm{m}$.

Film compositions were analyzed using X-ray photoelectron spectroscopy (XPS) on a Kratos Axis/HS system (XPS Axis HSi, Kratos Analytical, Manchester, UK). Samples were $\mathrm{Ar}^{+}$-ion etched before analysis to remove surface contaminants. The atomic percentages of nitrogen and oxygen were determined along with the metallic elements in 304 stainless steel ( $\mathrm{Fe}, \mathrm{Ni}$, and $\mathrm{Cr}$ ). The accuracy in nitrogen concentration measurements is estimated to be $\pm(2-4)$ at.\% N. X-ray diffraction analysis of the films was first carried out using a Shimadzu XRD-6100 (Shimadzu, Columbia, MD, USA) using $\mathrm{CuK} \alpha$ radiation $(\lambda=0.1542 \mathrm{~nm})$ set up in the Bragg-Brentano configuration with a graphite diffracted-beam monochromator. Additional X-ray diffraction studies were carried out using a Bruker system (Bruker Inc., Madison, WI, USA) equipped with a Vantec-500 area detector. The goniometer used was equipped with a two-position $\chi$ stage, which for the present purposes was set at the $\chi=54.74^{\circ}$ position. The nominal detector distance was set at $8 \mathrm{~cm}$, and a CoK $\alpha$ X-ray tube was used in order to avoid fluorescence of Fe. The accuracy in the measurement of interplanar spacings for this system is discussed in Appendix A. Further details on the analysis of the area detector data are outlined in the following section. 
Samples were deposited with substrate temperature and bias as the experimental variables. The temperatures used were between 150 and $350^{\circ} \mathrm{C}$, while the substrate bias was set at either ground or a level between -40 and $-160 \mathrm{~V}$. (Several samples were deposited at room temperature but had an amorphous structure and are therefore not considered here.) In the discussion which follows, the samples are denoted by temperature and bias (with zero bias indicating ground), e.g., sample S-150-60 indicates deposition using the 304 stainless steel target and $150{ }^{\circ} \mathrm{C}$ and $-60 \mathrm{~V}$ bias.

\section{Results}

\subsection{Film Compositions}

The relative proportions of $\mathrm{Fe}, \mathrm{Ni}$ and $\mathrm{Cr}$ found in the films generally reflected those of the target material, which for 304 stainless steel is nominally $74 \% \mathrm{Fe}, 18 \% \mathrm{Cr}$, and $8 \% \mathrm{Ni}$. The films also contained some oxygen, for samples deposited with a bias the average was 3.9 at.\%, while for samples deposited at ground the average was $16.2 \%$. The nitrogen levels in the films are shown in Figure 2 as a function of substrate temperature and bias. Two general trends are observed: first, at a given temperature, higher substrate bias levels results in a lower nitrogen content; this could be due to sputtering of nitrogen during deposition. This concept is supported by the fact that samples deposited at ground had the highest nitrogen content. Substrate temperature had less of an effect, mostly resulting in a in a slightly higher nitrogen level at higher temperatures. However, these trends were not significantly larger than the accuracy of the measurement.

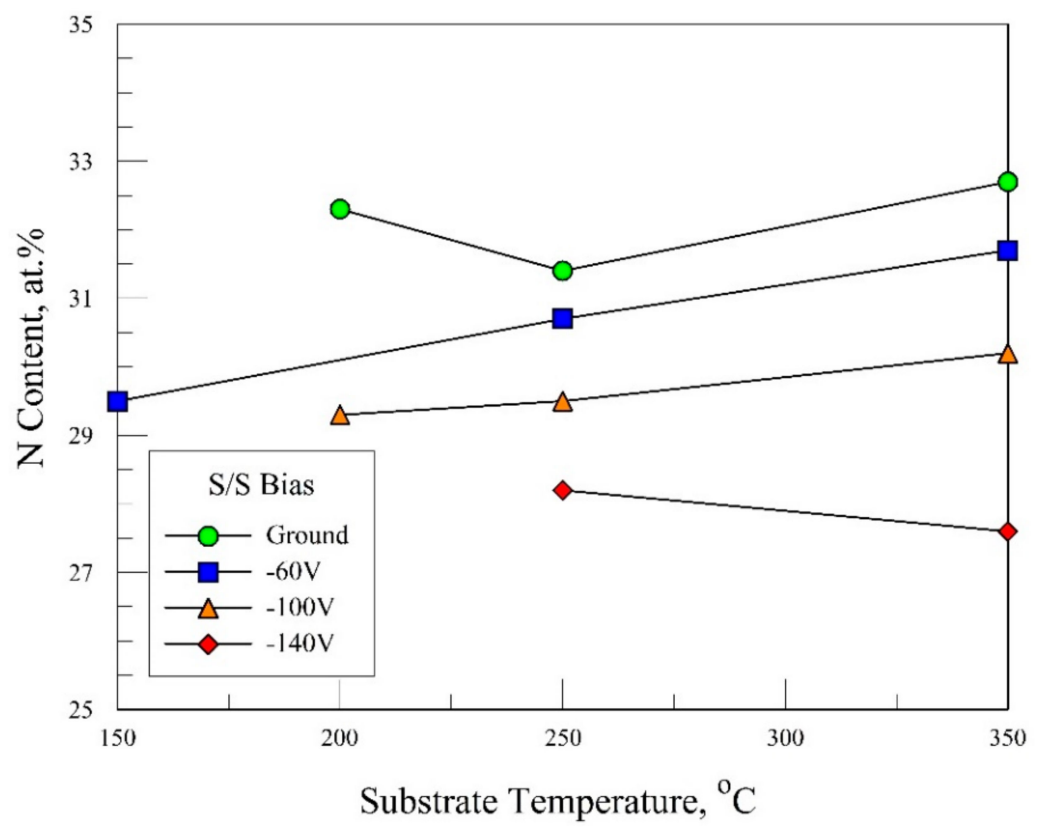

Figure 2. Nitrogen concentration in films deposited at different substrate temperature and bias levels. The major effect on composition is due to changes in substrate bias.

\subsection{X-ray Diffraction Using the Bragg-Bretano Method}

Figure 3a-d shows X-ray diffraction results collected on the Shimadzu diffractometer, which operates in the Bragg-Bretano configuration. Spectra are shown for the range of $2 \theta=30^{\circ}$ to $65^{\circ}$; the latter limit was chosen to avoid the highly intense $S i(400)$ substrate peak which appears at $2 \theta=69.20^{\circ}$. This also obstructed detection of the (220) peaks in the films, however, as verified later using the area detector XRD system, these peaks were either very weak or absent due to the film texture. Additional spectra were recorded in the range of $2 \theta=70^{\circ}$ to $120^{\circ}$, but again peaks in this range (primarily the (311) and (222) reflections) were generally weak and not used in the analysis. 
(a) Ground (OV)

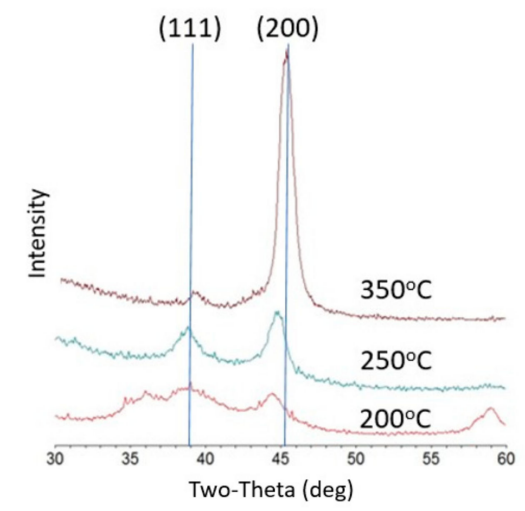

(c) $-100 \mathrm{~V}$

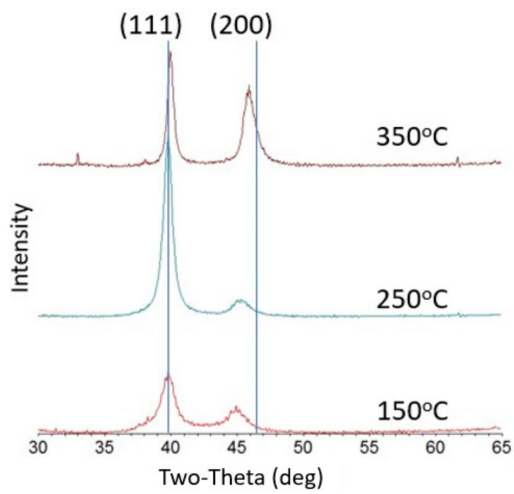

(b) $-60 \mathrm{~V}$

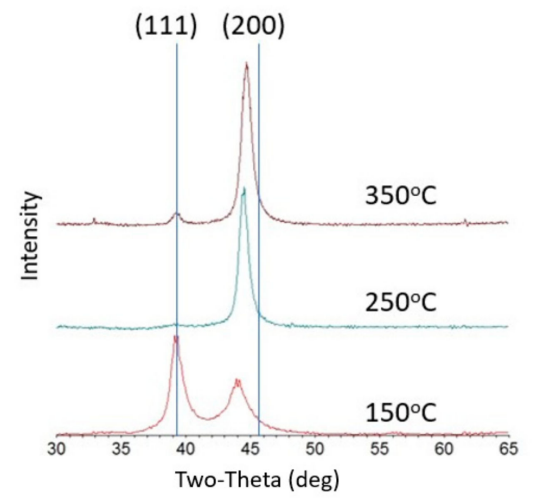

(d) $-140 \mathrm{~V}$

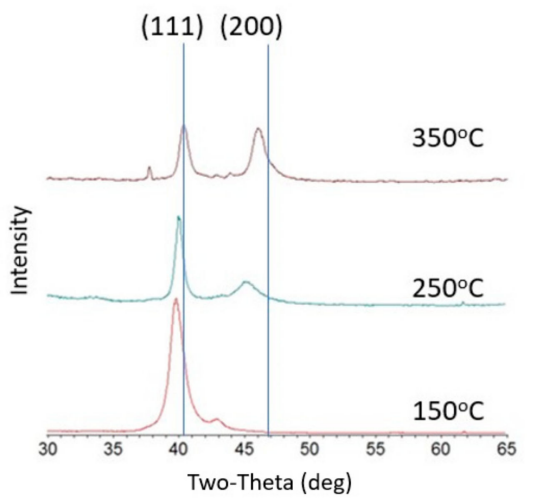

Figure 3. X-ray diffraction results for deposited films collected using the Bragg-Bretano configuration and $\mathrm{CuK} \alpha$ radiation. The spectra are shown for substrate bias levels of (a) $0 \mathrm{~V},(\mathbf{b})-60 \mathrm{~V},(\mathbf{c})-100 \mathrm{~V}$ and (d) $-140 \mathrm{~V}$, each at three different temperatures as shown. The positions of the (111) and (200) lines are shown and their locations based on a method described in the text.

Since there is no X-ray diffraction standard for S-phase structured stainless steel nitrides, analysis of the experimental patterns shown in Figure 3 require that an initial assumption be made to determine the appropriate lattice constant. Typically, the (200)/(400) peaks are assumed to have the anomalous shift so the (111) is used to determine the lattice constant (denoted $a_{111}$ ) and then remaining peak positions are determined based on this value and the assumption of an ideal FCC structure. This analysis was carried out by averaging the $a_{111}$ values for each set of films at the given bias and then displaying the (111) and (200) positions for each group in Figure 3.

The results show that the deviation in the (200) peak, compared to its expected position based on an ideal FCC structure, is typically $\sim 1^{\circ}-1.5^{\circ}-2 \theta$ lower. For samples deposited at ground $(0 \mathrm{~V})$ the peaks are broad, typically an effect of poor crystallinity; the sample deposited at $150{ }^{\circ} \mathrm{C}$ was too poorly crystalline for useful analysis and so a $200^{\circ} \mathrm{C}$ deposition was conducted instead. In comparison, the $-60 \mathrm{~V}$ samples show better crystallinity and a larger (200) peak shift. Figure $3 \mathrm{~d}$ ( $-140 \mathrm{~V}$ bias) also shows for the $150^{\circ} \mathrm{C}$ sample a small peak at $42.86^{\circ}$. While this could be a highly shifted (200) reflection, a more plausible explanation is that it is the result of small amount of $\mathrm{Cr}_{2} \mathrm{~N}$ formation, which according to PDF\#35-0803 has a (111) peak at $42.61^{\circ}$. The formation of this phase, not seen in other samples, is possibly due to the high bias and low temperature used as deposition conditions for this sample.

The XRD data in Figure 3 was analyzed and measurements of $\theta_{111}$ and $\theta_{200}$ were obtained allowing calculation of the $R_{B}$ parameter described in Equation (1). The results are shown in Figure 4 . It can be noted that the R-values are all greater than 0.75 . The effect of increasing substrate temperature at a given bias is to generally reduce the value of $R_{B}$, indicating a more normal cubic structure. The effect of substrate bias shows an increase of $R_{B}$ with bias level. The effect of bias was examined by closely by 
depositing samples at a constant temperature of $250^{\circ} \mathrm{C}$ and varying the bias levels from 0 to $-160 \mathrm{~V}$. The results are shown in Figure 5, where the data has also been fitted to a parabolic curve. For the sample deposited at $0 \mathrm{~V}$, the structure is very close to the ideal cubic structure, but at $-160 \mathrm{~V}$ a very large value of $R_{B}=0.795$ is obtained. Therefore, based on the results shown in Figures 3 and 4 , it can be concluded that lower temperatures and higher bias levels promote a larger deviation from the peak positions expected from a standard cubic structure.

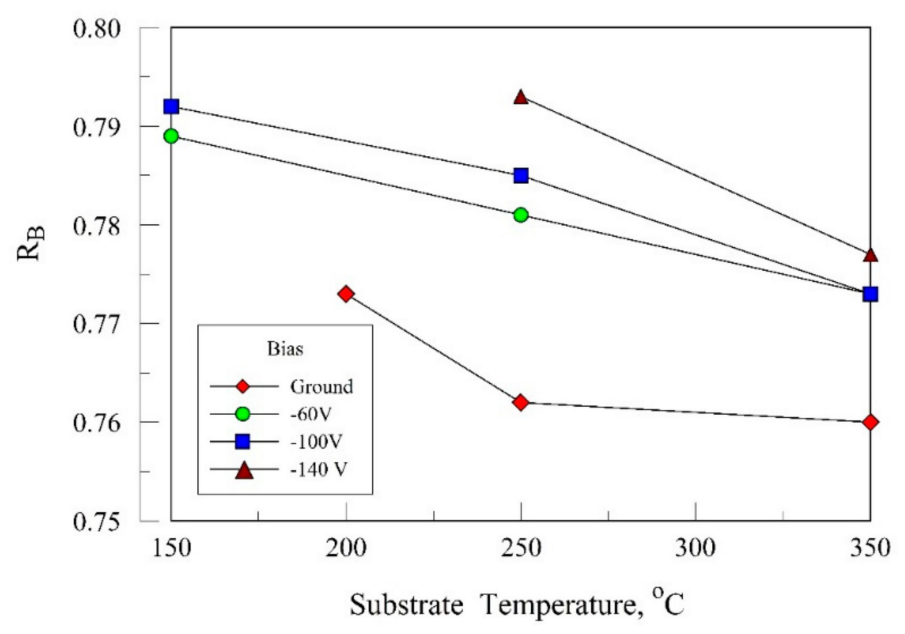

Figure 4. Measured values of $R_{B}$ for films deposited at various bias levels and substrate temperatures. The values of $R_{B}$ generally decrease with temperature and increase with substrate bias.

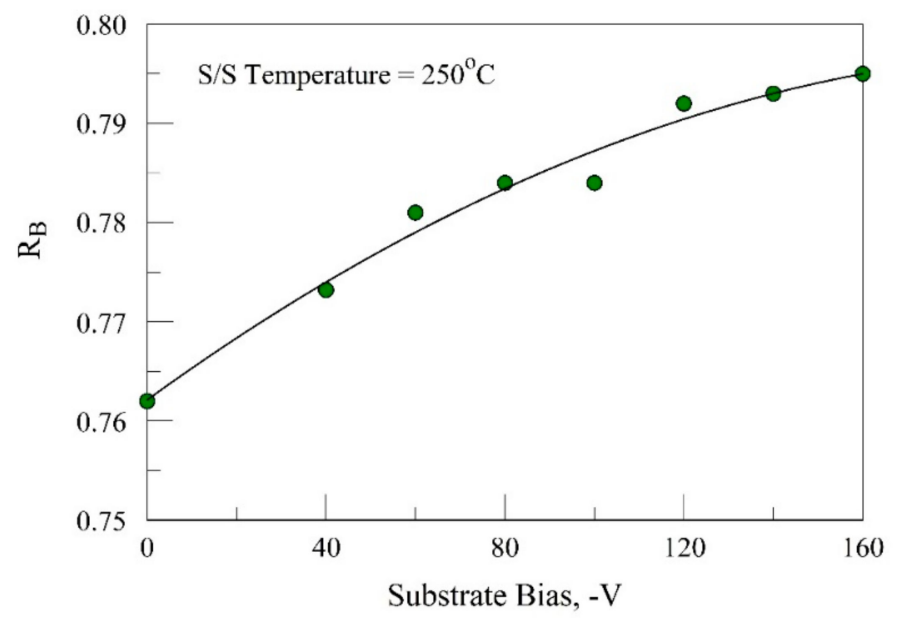

Figure 5. $R_{B}$ values for films deposited at $250{ }^{\circ} \mathrm{C}$ and substrate bias levels ranging from 0 to $-160 \mathrm{~V}$. The line shown is a parabolic fit to the data.

\subsection{Area-Detector Diffraction Studies}

Additional X-ray diffraction studies were carried out using a Bruker system equipped with a Vantec-500 area detector and a $\operatorname{CoK} \alpha$ radiation source. By setting the $\chi$-stage in the $54.74^{\circ}$ position, we were able to collect $X$-ray data in the range of $\psi \sim 0^{\circ}$ to $55^{\circ}$ (with $\psi=0^{\circ}$ being the normal Bragg-Brentano position). However, in some of the films, the presence of significant texture did not allow accurate measurements of peak positions at all $\psi$ angles. Therefore, only a subset of the deposited films could be analyzed by this technique, as indicated below.

In order to analyze samples, a set of four raw frames (at $90^{\circ}$ rotations about the sample normal) was first collected on the Vantec-500 detector which was set at a $2 \theta$ angle to allow optimal position of 
the two partial Debye rings corresponding to the (111) and (200) lines. The 20-peak positions (vs. $\psi$ ) for each ring were determined by using the Bruker GADDS stress analysis software (v. 4.1.51) for bi-axial $2 \mathrm{D}$ analysis, which divides the ring into 10 segments and integrates each segment $\left(0.1^{\circ}\right.$ step size) to determine the average peak position for that segment. The peak positions were converted to $d$-spacings, giving the $d_{200}$ and $d_{111}$ values vs. $\psi$ angle. The next step in the analysis was to obtain tables of $d_{111}$ and $d_{002}$ values as a function of $\varphi$, which is the angle between the (002) direction (c-axis) and the substrate plane. For $\mathrm{d}_{002}$ values the $\psi$ and $\varphi$ angles are the same, but for (111) reflections, the conversion $\varphi=54.74-\psi$ was necessary, as shown in Figure 1 . The $\mathrm{d}_{111}$ values were then reordered to list the results in increasing values of $\varphi$, from near zero to approximately $55^{\circ}$. While the angular range for $\varphi$ was similar for the $d_{111}$ and $d_{200}$ data sets, the average angle of each of the 10 integrated sections was not the same, so for further analysis the data were fit to a second-order polynomial ranging from $\varphi=0^{\circ}$ to $60^{\circ}$ in $5^{\circ}$ steps. The fitted $\mathrm{d}_{111}$ and $\mathrm{d}_{002}$ values were first used to calculate the $a_{111}$ and $a_{002}$ values based on the assumption of a cubic lattice. They were then used to calculate the parameters for a tetragonal lattice, $a_{200}(=a)$ and $a_{002}(=c)$, using the relation $c=2 d_{002}$ and the $a$ value obtained from Equation (3). In addition, the volume of the tetragonal unit cell was calculated using the equation $V=a^{2} c$.

Figure 6 plots the values of $a_{111}$ and $a_{200}$ based on a cubic lattice assumption. As expected, the $a_{200}$ values are always higher than $a_{111}$. The degree of separation between the curves is consistent with Figure 4 . The variations of $a_{h k l}$ with $\varphi$ provides important information on possible residual stress effects and will be discussed further in the following section. Comparing actual $R_{B}$ values from the area detector data (at $\psi=0$ ) with those in Figure 4, it was found that the area detector results gave $R_{B}$ values $5 \%-6 \%$ higher in all four cases. Figure 6 also shows that, in all cases, the $a$-values decrease with increasing $\varphi$, although not at the same rate for all samples.

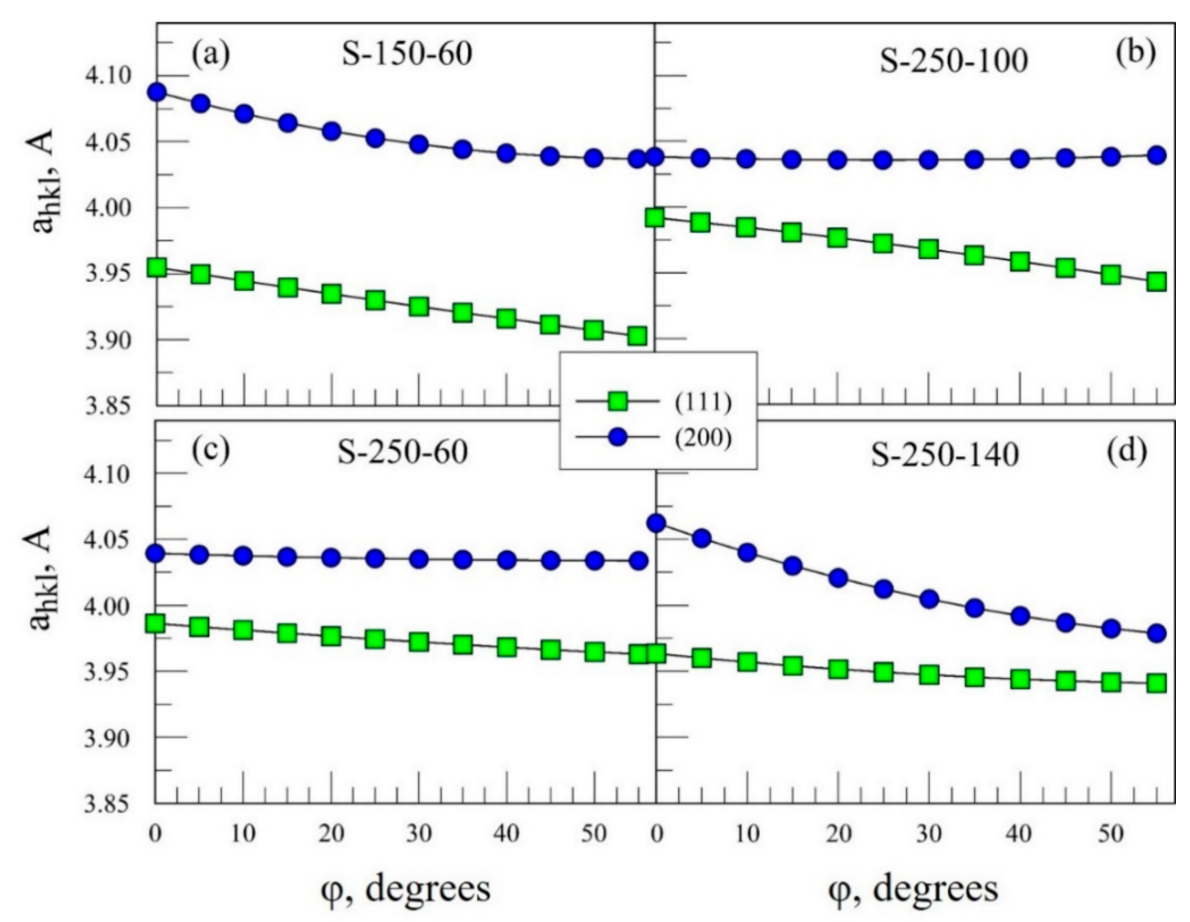

Figure 6. Lattice constant values as calculated from the positions of the (111) and (200) peaks, shown for four different deposition conditions (a-d). The lattice constants shown here were calculated based on the assumption of a cubic structure. The values are shown as a function of $\varphi$; at $\varphi=0$ the [002] direction is parallel to the surface plane normal.

Next, assuming a tetragonal lattice, the $c / a$ values were calculated and the results are shown in Figure 7. Overall, the values range from about 1.01 to 1.05 . The $\varphi$-dependence is varied, ranging from 
almost constant (S-150-60) to strongly decreasing (S-250-140) to increasing (S-250-100). The values tend to show as slight decrease in $c / a$ near $30^{\circ}$, but this has be determined to be due to a slight (and non-correctable) misalignment of the detector. Figure 8 shows the unit cell volume as a percentage change from the initial $(\varphi=0)$ volume. In all cases, the unit cell volume decreases with increasing $\varphi$, with the maximum values shown (at $\varphi=55^{\circ}$ ) ranging from about $-1 \%$ to $-4 \%$. Sample S-150-60 showed the largest percentage decrease, and was also the sample with the highest c/a values.

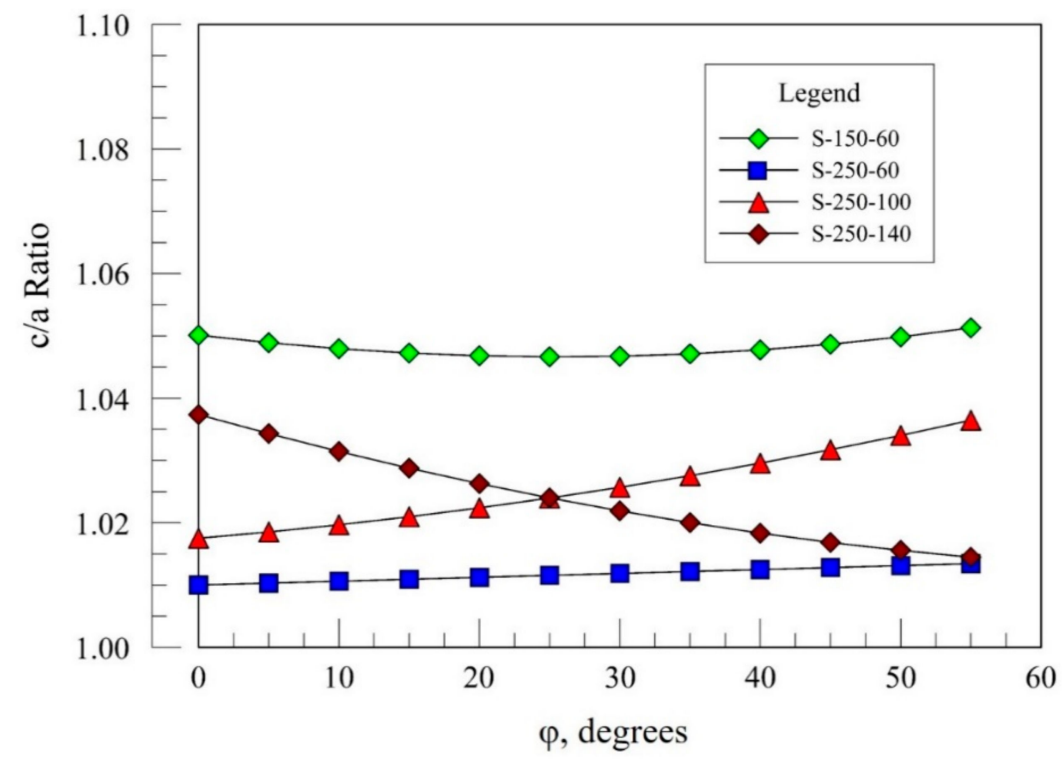

Figure 7. Calculated $c / a$ ratio as determined from area-detector diffraction analysis. The $c / a$ ratios are all greater than 1.0 but the dependence on $\varphi$ varies considerably in both magnitude and rate of change with $\varphi$.

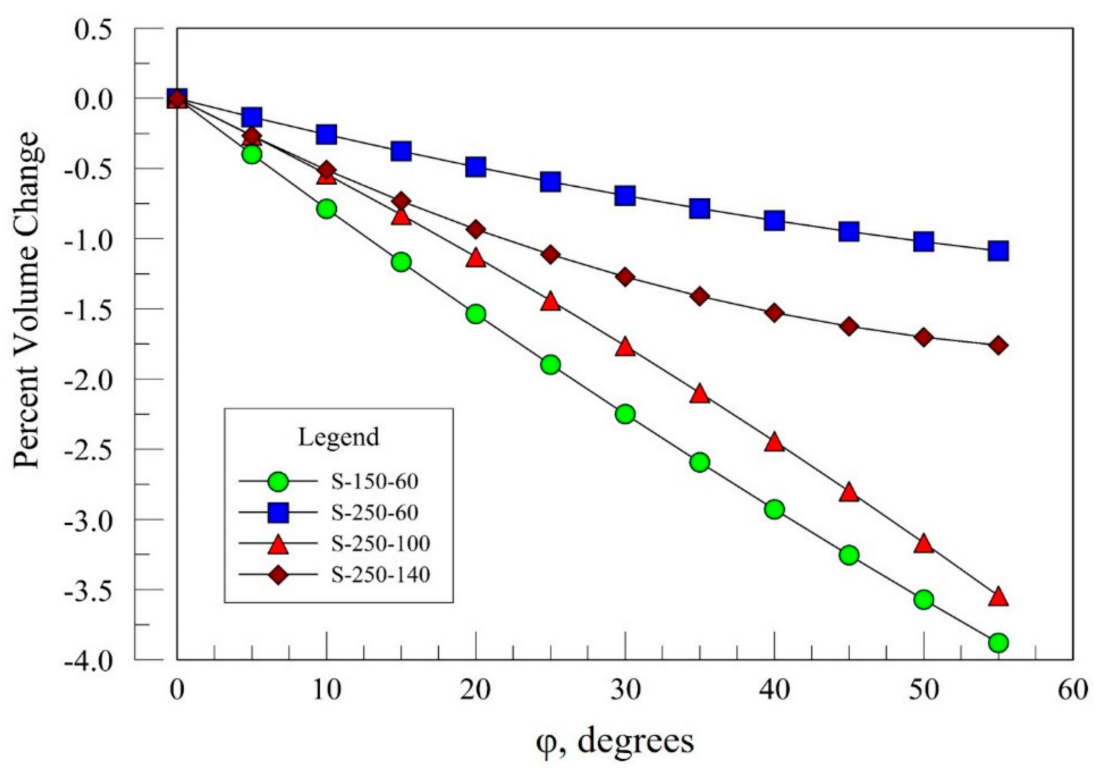

Figure 8. Percentage volume change for the tetragonal lattice based on area detector X-ray diffraction data. In all cases, the volume decreased as the $\varphi$ angle increased. The decrease is most significant for sample S-150-60, which had the highest c/a ratio.

Having calculated c/a ratios for these samples, we can calculate the expected separation between $2 \theta_{002}$ and $2 \theta_{002}$, denoted here as $\Delta 2 \theta$. Values were calculated for the four samples examined in this 
section, and a range of values was obtained depending of the $\psi$ values. The results are shown in Table 1. In general, even for broad peaks of the nature shown in Figure 4, the (002)/(200) peak split is large enough in most cases to be readily observed. Yet, examination of the entire area detector field showed no extra peaks were present.

Table 1. Expected for (200)/(002) peak split.

\begin{tabular}{cc}
\hline Sample & $\boldsymbol{\Delta} \mathbf{2 \theta}$ Range \\
\hline S-60-150 & $2.8-2.9^{\circ}$ \\
\hline S-60-250 & $0.6-0.8^{\circ}$ \\
\hline S-100-250 & $1.4-2.2^{\circ}$ \\
\hline S-140-250 & $0.84-2.1^{\circ}$ \\
\hline
\end{tabular}

\section{Discussion}

In this study the nature of the well-known diffraction anomaly observed in samples of expanded austenite or the S-phase in nitrogen supersaturated stainless steels has been studied in sputter-deposited thin films. The use of this thin film deposition technique allows us to examine the effects of variations in the substrate temperature and bias, and films can be deposited at temperatures lower than those typically used in plasma nitriding of bulk samples. Also, in contrast to most plasma-nitriding methods, sputter deposition results in compositionally uniform samples, and therefore simplifies the analysis of X-ray diffraction data.

The extent of the diffraction anomaly was first characterized by calculating " $R_{B}$-values" from standard Bragg-Bretano X-ray diffraction patterns, with $R_{B}=0.75$ indicating a normal cubic lattice. As shown in Figures 4 and 5 , the $R_{B}$-values increased with substrate bias and decreased with increasing temperature. These results can be considered in parallel with the nitrogen content in the films (Figure 2), which decreases with substrate bias but where only a small temperature effect is observed. The increase in $R_{B}$ with bias, as well as the decrease in nitrogen content indicates that less $\mathrm{N}$ in the lattice increases the diffraction anomaly. Kappaganthu and Sun [15] deposited similar films by reactive sputtering using a range of nitrogen gas concentrations and obtained $R_{B}$-values (as calculated based on their data) similar to those reported here, but also obtained stoichiometric films which had $R_{B}$-values of 0.75 . These results support the conclusion that the extent of the diffraction anomaly is proportional to the deficiency of nitrogen in the lattice. However, the results shown in Figure 4 also show a trend of decreasing $R_{B}$ with increasing temperature in samples that had a relatively constant $\mathrm{N}$ content. It is well established, via the zone model, that higher deposition temperatures increases the film density and grain size while reducing film defects such as intergranular voids, faceted columns, and feather-like structures [37]. However, the presence of such defects is not known to produce a diffraction anomaly. In addition, the results shown in Figure 4 appear to suggest contradictory evidence for this hypothesis: $R_{B}$ decreases with increasing substrate deposition temperature, which should help densify films, but increases with bias, which also increases film density. The possibility of peak shifts due to stacking fault defects, as discussed in the Introduction, may explain the temperature effect but detailed microscopic examinations of our samples will be needed to verify this.

One explanation for the diffraction anomaly is that (002) and (111)-oriented grains have different nitrogen concentrations, and therefore different lattice constants; when measured using the Bragg-Brentano method each peak would represent different grains. Therefore, it is important to obtain the (111) and (002) interplanar spacings form similarly-oriented grains. This was done here using the area detector diffraction method, where interplanar spacings from planes oriented away from the substrate surface orientation could be measured. This allowed the interplanar spacings of (111) and (002) planes to be measured for grains of similar orientations. The results were first analyzed assuming a cubic structure, as shown in Figure 6. As expected, the $a_{111}$ and $a_{200}$ had different values over the range of $\varphi$ values. Generally, these $a_{h k l}$ either decreased or remained constant with $\varphi$ but 
were still significantly different over the range of $\varphi$. Physically, this means that measured $a_{111}$ and $a_{200}$ values were truly different within a single grain and not due to the fact that each was measure from grains of different orientations.

The variations of $a_{h k l}$ with $\varphi$ observed in Figure 6 can be considered as possible effects of residual stress. We first consider the (002) planes parallel to the substrate normal, as shown in grain 1 in Figure 1. For a compressive (in-plane) residual stress, these planes would have a higher value of $a_{002}$ compared to the unstressed state. For (002) planes tilted away from the substrate normal (increasing $\varphi$ ), as shown in grain 2, the value of $a_{002}$ will decrease. This is observed for Figure 6a, $\mathrm{d}$ (the curves in Figure $6 b, c$ suggest little or no stress is present in these cases). For the (111) planes, the $\varphi=0$ case refers to the tilted case (as shown in grain 1) and as $\varphi$ increases the (111) planes become increasingly parallel to the surface. Therefore, when plotting the data as $a$ vs. $\varphi$, the $a_{111}$ values should increase with increasing $\varphi$ (for a compressive stress). This is contrary to the data shown in Figure 6, where $a_{111}$ is always decreasing. Therefore, while residual stress may impact the curves, it alone cannot explain the data shown in Figure 6.

Next, the possibility of explaining the peak shift using a tetragonal structure was explored. Using Equation (3), the $c / a$ values were calculated as shown in Figure 7 . The values were all greater than one, however, no consistent trend was observed when examining the $\varphi$-dependence. In fact, results ranged from being relatively constant to increasing to decreasing. However, calculation of relative unit cell volume (Figure 8) did show a consistently decreasing value with $\varphi$ although with varying magnitudes. This is consistent with the observation that the diffusion of $\mathrm{N}$ is highest for (002) oriented grains, giving these grains a higher $\mathrm{N}$ concentration and larger lattice constant. Even without the tetragonal lattice assumption (as observed in the data in Figure 6), the largest lattice constants are generally found in the [002]-oriented grains.

The tetragonal model can also be used to calculate the location of the additional peaks that should be observed, and Table 1 shows calculations of the expected peak split for the $(002) /(200)$ reflections. However, no additional peaks were observed. Despite the fact that the d-spacings from the (111) and (002) peaks are inconsistent with the cubic structure, no evidence for a non-cubic structure could be found. This suggests that the anomaly is related to defects created by sub-stoichiometric N content, which is supported by the decreasing $R_{B}$ values with increasing substrate temperature.

\section{Conclusions}

Thin films of nitrogen-enhanced 304 stainless steels were deposited by magnetron sputtering using primarily substrate temperature and bias as deposition variables. Samples were analyzed using $X$-ray diffraction methods in order to help understand the origin of the well-known diffraction anomaly commonly observed in S-phase samples.

The films were found to contain between 28 and 32 at.\% nitrogen. Higher substrate bias levels results in a lower nitrogen contents, possibly due to sputtering of nitrogen during deposition. Substrate temperature had only a minor effect, mostly resulting in a in a slightly higher nitrogen level at higher temperatures.

X-ray diffraction using the Bragg-Brentano method was carried out with particular focus on measuring the positions of the (111) and (002) peaks. Using these results a term denoted $R_{B}$, which is related to the extent of the diffraction anomaly, was calculated as a function of deposition conditions. It was found that the $R_{B}$ values decreased with substrate temperature, and increased strongly with substrate bias.

Area detector diffractometry studies were conducted and analyzed using a tetragonal structure model. This allowed calculation of $c / a$ ratios and the expected (002)/(200) peak split. However, no peak split was observed, indicating the tetragonal structure model is not valid for these samples. This also suggests that a defect-based hypothesis is more viable as an explanation for the diffraction anomaly. 
Author Contributions: Formal analysis, F.I.A. and J.E.K.; Investigation, F.I.A.; Methodology, J.E.K.; Resources, J.E.K.; Writing - original draft, F.I.A.; Writing—review \& editing, J.E.K. All authors have read and agreed to the published version of the manuscript.

Funding: This research received no external funding.

Conflicts of Interest: The authors declare no conflict of interest.

\section{Appendix A}

The discrepancy between the $a_{111}$ and $a_{200}$ measured lattice constants, as shown for example in Figure 6, needs to be considered in comparison to the accuracy typical of XRD measurements. To examine this more closely, we measured the $a_{111} / a_{200}$ lattice constants for a Cu powder, for which the calculated lattice constants should be identical. Data were acquired in a manner similar to that for Figure 6 (Using the Bruker XRD instrument) and processed in a similar way to obtain $a$ vs. $\varphi$. The results are shown below in Figure A1, where the scale for the $a$-values was chosen to be similar to that in Figure 6 . The discrepancy is at most $\sim 0.02 \mathrm{~A}$, whereas the difference between $a_{111}$ and $a_{200}$ in Figure 6 is typically between $0.05-0.1 \mathrm{~A}$. This supports the fact that the $a_{111} / a_{200}$ lattice constant differences shown in Figure 6 is not due to measurement inaccuracies.

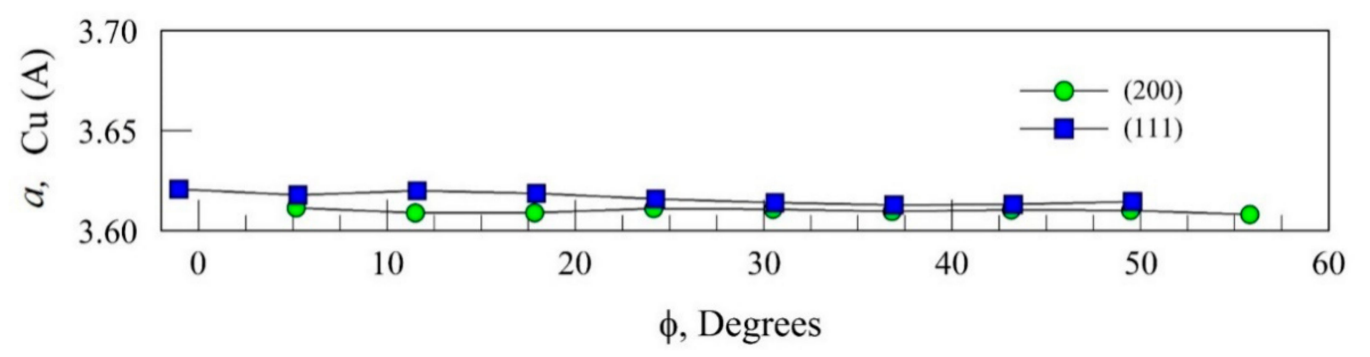

Figure A1. Measured lattice constants for a $\mathrm{Cu}$ powder based on the (111) and (200) reflections vs. $\varphi$, angle increased. The figure demonstrates the typical accuracy of the lattice constant measurement.

\section{References}

1. Zhang, Z.L.; Bell, T. Structure and corrosion resistance of plasma nitrided stainless steels. Surf. Eng. 1985, 1, 131-136. [CrossRef]

2. Ichii, K.; Fujimura, K.; Takase, T. Sturcture of the ion-nitrided layer of 18-8 stainless steel. Technol. Rep. Kansai Univ. 1986, 27, 135-144.

3. Ozturk, O.; Williamson, D.L. Phase and composition depth distribution analyses of low energy, high flux N implanted stainless steel. J. Appl. Phys. 1995, 77, 3839-3850. [CrossRef]

4. Williamson, D.L.; Davis, J.A.; Wilber, P.J.; Vajo, J.J.; Wei, R.; Matossian, J.N. Relative roles of ion energy, ion flux, sample temperature in low-energy nitrogen ion implantation of Fe-Cr-Ni stainless steel. Nucl. Inst. Methods Phys. Res. B 1997, 127-128, 930-934. [CrossRef]

5. Wei, R.; Vajo, J.J.; Matossian, J.N.; Wilbur, P.J.; Davis, J.A.; Williamson, D.L.; Collins, G.A. A comparative study of beam ion implantation, plasma ion implantation, and nitriding of AISI 304 stainless steel. Surf. Coat. Technol. 1996, 83, 235-242. [CrossRef]

6. Samandi, M.; Shedden, B.A.; Smith, D.I.; Collins, G.A.; Hutchings, R.; Tendys, J. Microstructure, corrosion, and tribological behaviour of plasma immersion ion-implanted austenitic stainless steel. Surf. Coat. Technol. 1993, 59, 261-266. [CrossRef]

7. Menthe, E.; Rie, K.-T.; Schultze, J.W.; Simson, S. Structure and properties of plasma-nitrided stainless steel. Surf. Coat. Technol. 1995, 74-75, 412-416. [CrossRef]

8. Mändl, S.; Günzel, R.; Richter, E.; Möller, W. Nitriding of austenitic stainless steels using plasma immersion ion implantation. Surf. Coat. Technol. 1998, 372, 100-101. [CrossRef]

9. Blawert, C.; Mordike, B.L. Nitrogen plasma immersion ion implantation for surface treatment and wear protection of austenitic stainless steel X6CrNiTi1810. Surf. Coat. Technol. 1999, 116-119, 352-360. [CrossRef] 
10. Leyland, A.; Lewis, D.B.; Stevenson, P.R.; Matthews, A. Low temperature plasma diffusion treatment of stainless steels for improved wear resistance. Surf. Coat. Technol. 1993, 62, 608-617. [CrossRef]

11. Saker, A.; Leroy, C.; Michel, H.; Frantz, C. Properties of sputtered stainless-steel coatings and structural analogy with low temperature plasma nitride layers of austenitic steels. Mater. Sci. Eng. 1991, A140, 702. [CrossRef]

12. Bourjot, A.; Foos, M.; Frantz, C. Basic Properties of Sputtered 310 Stainless Steel-Nitrogen Coatings. Surf. Coat. Technol. 1990, 43-44, 533-542. [CrossRef]

13. Shedden, B.A.; Kaul, F.N.; Samandi, M.; Window, B. The role of energetic neutrals in reactive magnetron sputtering of nitrogen-doped austenitic stainless steel coatings. Surf. Coat. Technol. 1997, 97, 102-108. [CrossRef]

14. Terwagne, G.; Hody, H.; Colaux, J. Structural and quantitative analysis of stainless steel coatings deposited by DC-magnetron sputtering in a reactive atmosphere. Surf. Coat. Technol. 2002, 383, 174-175. [CrossRef]

15. Kappaganthu, S.R.; Sun, Y. Formation of an MN-type cubic nitride phase in reactively sputtered stainless steel-nitrogen films. J. Cryst. Growth 2004, 267, 385-393. [CrossRef]

16. Kappaganthu, S.R.; Sun, Y. Influence of sputter deposition conditions on phase evolution in nitrogen doped stainless steel films. Surf. Coat. Technol. 2004, 198, 59-63. [CrossRef]

17. Marchev, K.; Hidalgo, R.; Landis, M.; Vallerio, R.; Cooper, C.V.; Giessen, B.C. The metastable $m$ phase layer on ion-nitrided austenitic stainless steels Part 2: Crystal structure ad observation of its two-directional orientation anisotropy. Surf. Coat. Technol. 1999, 67, 112. [CrossRef]

18. Marchev, K.; Landis, M.; Vallerio, R.; Cooper, C.V.; Giessen, B.C. The $m$ phase layer on ion-nitrided austenitic stainless steels (III): An epitaxial relationship between the $m$ Phase and the $\gamma$ parent phase and a review of structural identification of this phase. Surf. Coat. Technol. 1999, 116, 184-188. [CrossRef]

19. Bacci, T.; Borgioli, F.; Galvanetto, E.; Pradelli, G. Glow-discharge nitriding of sintered stainless steels. Surf. Coat. Technol. 2001, 139, 251-256. [CrossRef]

20. Fewell, M.P.; Mitchell, D.R.G.; Priest, J.M.; Short, K.T.; Collins, G.A. The nature of expanded austenite. Surf. Coat. Technol. 2000, 131, 300-306. [CrossRef]

21. Fewell, M.P.; Priest, J.M. Higher-order diffractometry of expanded austenite using synchrotron radiation. Surf. Coat. Technol. 2008, 202, 1802. [CrossRef]

22. Blawert, C.; Kalvelage, H.; Mordike, B.L.; Collings, G.A.; Short, K.T.; Jirásková, Y.; Schneeweiss, O. Nitrogen and carbon expanded austenite produced by $\mathrm{PI}^{3}$. Surf. Coat. Technol. 2001, 136, 181-187. [CrossRef]

23. Christiansen, T.; Somers, M.A.J. On the crystallographic structure of the S-phase. Scr. Mater. 2004, 50, 35-37. [CrossRef]

24. Xu, X.L.; Yu, Z.W.; Wang, L.; Hei, Z.K. Microstructural characterization of plasma nitride austenitic stainless steel. Surf. Coat. Technol. 2000, 132, 270-274. [CrossRef]

25. Warren, B.E. X-ray Diffraction; Addison-Wesley: Boston, MA, USA, 1969; pp. 275-298.

26. Xu, X.L.; Yu, Z.W.; Wang, L.; Qiang, J.; Hei, Z.K. Phase depth distribution characteristics of the plasma nitrided layer on AISI 304 stainless steel. Surf. Coat. Technol. 2003, 162, 242-247. [CrossRef]

27. Stroz, D.; Psoda, M. TEM studies of plasma nitride austenitic stainless steel. J. Microsc. 2010, 237, $227-231$. [CrossRef]

28. Brink, B.K.; Stahl, K.; Christiansen, T.L.; Oddershede, J.; Winther, G.; Somers, M.A.J. On the elusive structure of expanded austenite. Scr. Mater. 2017, 131, 59-62. [CrossRef]

29. Velterop, L.; Delhez, R.; deKeijser, T.H.; Mittemeijer, E.J.; Reefman, D. X-ray diffraction analysis of stacking and twin faults in f.c.c. metals: A revision and allowance for texture and non-uniform fault probabilities. J. Appl. Cryst. 2000, 33, 296-306. [CrossRef]

30. Grigull, S.; Parascandola, S. Ion-intriding induced plastic deformation in austenitic stainless steel. J. Appl. Phys. 2000, 88, 6925-6927. [CrossRef]

31. Abrasonis, G.; Riviere, J.P.; Templier, C.; Declemy, A.; Pranevicius, L.; Milhet, X. Ion beam nitriding of single and polycrystalline austenitic stainless steel. J. Appl. Phys. 2005, 97, 083531. [CrossRef]

32. Brink, B.K.; Stahl, K.; Christiansen, T.L.; Fradsen, C.; Hansen, M.F.; Somers, M.A.J. Composition-dependent variation of magnetic properties and interstitial ordering in homogeneous expanded austenite. Acta Mater. 2016, 106, 32-39. [CrossRef]

33. Oddershede, J.; Christiansen, T.L.; Stahl, K.; Somers, M.A.J. EXAFS investigation of low temperature nitride stainless steel. J. Mater. Sci. 2008, 43, 5358-5367. [CrossRef] 
34. Czerwiec, T.; Andrieux, A.; Marcos, G.; Michel, H.; Bauer, P. Is "expanded austenite" really a solid solution? Mössbauer observation of an annealed AISI 316L nitride sample. J. Alloys Compd. 2019, 811, 151972. [CrossRef]

35. Christiansen, T.L.; Hummelshøj, T.S.; Somers, M.A.J. Expanded austenite, crystallography and residual stress. Surf. Eng. 2010, 26, 242-247. [CrossRef]

36. Alresheedi, F.I.; Krzanowski, J.E. Structure and morphology of stainless steel coatings sputter-deposited in a nitrogen/argon atmosphere. Surf. Coat. Technol. 2017, 314, 105-112. [CrossRef]

37. Mayrhofer, P.H.; Mitterer, C.; Hultman, L.; Clemens. H. Microstructural design of hard coatings. Prog. Mater. Sci. 2006, 51, 1032-1114. [CrossRef]

Publisher's Note: MDPI stays neutral with regard to jurisdictional claims in published maps and institutional affiliations.

(C) 2020 by the authors. Licensee MDPI, Basel, Switzerland. This article is an open access article distributed under the terms and conditions of the Creative Commons Attribution (CC BY) license (http://creativecommons.org/licenses/by/4.0/). 